\title{
The use of induced hypothermia after cardiac arrest: a survey of Canadian emergency physicians
}

\author{
Joel Kennedy, BScH; ${ }^{*}$ Robert S. Green, MD; ${ }^{* \dagger}$ Robert Stenstrom, MD, PhD; $;$ on behalf of the CAEP \\ Critical Care Committee
}

\begin{abstract}
Objective: Inducing mild hypothermia in survivors of cardiac arrest has been demonstrated to improve outcomes. Despite this, other studies have found that few resuscitation physicians have used hypothermia in clinical practice. The objective of this study was to characterize the use of induced hypothermia by Canadian emergency physicians.

Methods: An internet-based survey was distributed to all members of the Canadian Association of Emergency Physicians (CAEP). Participants were asked about their experience with, methods for and barriers to inducing hypothermia.

Results: Of the 1328 CAEP members surveyed, 247 (18.6\%) responded, with the majority working in academic centres $(60.3 \%)$. Ninety-five out of 202 respondents $(47.0 \%, 95 \%$ confidence interval [Cl] 40.8\%-53.2\%) indicated that they had induced hypothermia in clinical practice and 86 of 212 $(40.6 \%, 95 \% \mathrm{Cl} 34.0 \%-47.2 \%)$ worked in a department that had a policy or protocol for the use of induced hypothermia. The presence of a departmental policy or protocol was strongly associated with the use of induced hypothermia (unadjusted odds ratio 10.5, 95\% CI 5.3-20.8). Barriers against induced hypothermia cited by respondents included a lack of institutional policies and protocols $(38.9 \%)$, and of resources $(29.4 \%)$. Lack of support from consultants was relatively uncommon $(8.7 \%)$ in Canadian practice.

Conclusion: Only one-half of Canadian emergency physicians report that they have used therapeutic hypothermia in practice. Emergency departments should develop policies or protocols for inducing hypothermia in cardiac arrest survivors to optimize patient outcomes.
\end{abstract}

Keywords: induced hypothermia, emergency medicine, cardiac arrest, policy protocol

RÉSUMÉ

Objectif: Même si l'on a démontré que l'induction d'une hypothermie légère chez les survivants d'un arrêt cardiaque améliore l'issue, des études ont révélé que peu de médecins en réanimation ont en pratique utilisé I'hypothermie. Cette étude visait à caractériser l'utilisation de l'hypothermie induite par les médecins d'urgence au Canada.

Méthodes: On a distribué par Internet un questionnaire à tous les membres de I'Association canadienne des médecins d'urgence (ACMU), à qui on a demandé d'indiquer leur expérience de I'hypothermie induite, les méthodes utilisées et les obstacles à l'utilisation de cette technique.

From the *Department of Emergency Medicine, Dalhousie University, the tDepartment of Internal Medicine, Division of Critical Care Medicine, Dalhousie University, Halifax, NS, and ¥St. Paul's Hospital and the University of British Columbia, Vancouver, BC

Received: Mar. 30, 2007; revisions received: Aug. 6, 2007; accepted: Aug. 6, 2007

This article has been peer reviewed.

CJEM 2008;10(2):125-30 
Résultats: Sur les 1328 membres de l'ACMU sondés, les 247 (18,6 \%) qui ont répondu travaillaient en majorité dans des centres universitaires (60,3\%). Quatre-vingt-quinze répondants sur $202(47,0 \%$, intervalle de confiance [IC] à $95 \%, 40,8 \%-53,2 \%)$ ont indiqué qu'ils avaient utilisé dans la pratique I'hypothermie induite, et 86 sur $212(40,6 \%$, IC à $95 \%, 34,0 \%-47,2 \%)$ travaillaient dans un service qui avait une politique ou un protocole sur l'utilisation de l'hypothermie induite. L'existence d'une politique ou d'un protocole dans un département était fortement associée à I'utilisation de I'hypothermie induite (coefficient de probabilité non rajusté 10,5, IC à $95 \%$, 5,3-20,8). Les obstacles à I'utilisation de I'hypothermie induite mentionnés par les répondants comprenaient l'absence de politique et de protocole de l'établissement $(38,9 \%)$ et le manque de ressources $(29,4 \%)$. Le manque d'appui des médecins-conseils était relativement peu courant $(8,7 \%)$ dans la pratique canadienne.

Conclusion : La moitié seulement des médecins d'urgence du Canada signalent avoir utilisé I'hypothermie thérapeutique dans leur pratique. Les services d'urgence devraient établir des politiques ou des protocoles sur l'induction de l'hypothermie chez les survivants à un arrêt cardiaque afin d'optimiser l'issue pour le patient.

\section{Introduction}

Out-of-hospital sudden cardiac arrests have been reported to occur in 40 to 130 per 100000 population per year in industrialized countries ${ }^{1-3}$ and less than 5\% of these people survive. ${ }^{4}$ Improved outcomes are associated with early bystander cardiopulmonary resuscitation (CPR), ${ }^{5}$ early defibrillation, ${ }^{5,6}$ administration of advanced life support ${ }^{7}$ and the induction of mild hypothermia. ${ }^{8,9}$

Based on 2 prospective trials that demonstrated improved neurologic outcomes in patients managed with induced hypothermia $\left(32^{\circ} \mathrm{C}-34^{\circ} \mathrm{C}\right)$ for $12-24$ hours, ${ }^{8,9}$ the International Liaison Committee on Resuscitation (ILCOR) and the American Heart Association (AHA) recommend (grade IIa, i.e., the benefits exceed the risks) induced hypothermia for cardiac arrest victims with a rhythm of ventricular fibrillation. ${ }^{10}$ AHA, ILCOR and the Canadian Association of Emergency Physicians (CAEP) Critical Care Committee support the use of induced hypothermia in unconscious patients after ventricular fibrillation arrest. ${ }^{10-13}$ The CAEP Critical Care Committee has also advocated the use of an algorithm for the induction of hypothermia in the emergency department (ED). ${ }^{14}$

However, the translation of this knowledge into practice has been limited. One survey reported that only one-quarter of US and one-third of non-US physicians had initiated mild hypothermia in cardiac arrest patients. ${ }^{15}$ Respondents cited "lack of substantial data," "too technically difficult" and "never considered a treatment option" as reasons for not initiating hypothermia. ${ }^{15,16}$

Currently, there are few data on the use of induced hypothermia in Canada. The objective of this study was to characterize the use of induced hypothermia by Canadian emergency physicians.

\section{Methods}

\section{Setting}

This survey of CAEP members was conducted online. The study protocol was approved by the Capital Health Research Ethics Board (Halifax, Nova Scotia).

\section{Survey development}

A survey was developed using SurveyMonkey.com (available: www.surveymonkey.com) by members of the CAEP Critical Care Committee. Questions consisted of multiple choice, multi-answer multiple choice and open-ended response. Participants were asked their age, location and training. They were also asked their experience with, techniques for, barriers to and concerns about using induced hypothermia.

\section{Sampling}

Based on the sample size calculation, 171 respondents would provide a $95 \%$ confidence interval (CI) width of 15 percentage points around a response proportion near $50 \%$. As the response rate for this survey was uncertain, all CAEP members, including attending physicians, residents and medical students as of 2006 were solicited. Distribution of the surveys was controlled by CAEP head office staff only, ensuring respondent anonymity. An invitation to participate and a link to the survey were sent on 4 occasions via electronic mail between July and September 2006. Participation was voluntary and anonymous, and safeguards were put in place to prevent duplicate responses.

\section{Data analysis}

Demographic and other response data were tallied using percentages and $95 \%$ CIs on percentages. 
In order to evaluate barriers to the implementation of induced hypothermia, logistic regression using a forward stepwise selection procedure was used, with a $p$ value $\leq 0.15$ required for a predictor variable to be retained in the model. Four potential predictor variables were chosen on the basis of plausibility: hospital type (academic, nonacademic), emergency medicine (EM) training (CCFP, CCFP[EM], FRCP, others) ED visits per year $(<10000$; $10000-30000 ; 30000-50000 ;>50000)$ and if the hospital had a protocol or policy in place for cooling. Statistica (StatSoft Inc, Tulsa, Oklahoma), BMDP (Statistical Solutions, Saugus, Massachusetts) and Egret (Cytel Statistical Software and Services, Cambridge, Massachusetts) software were used for all analyses.

\section{Results}

Of 1328 CAEP members invited to participate, 247 members completed the survey (18.6\% response rate). Respondents included attending EM physicians (93.3\%) and residents $(6.7 \%)$. Table 1 lists the demographics of the respondents.

The proportion of respondents who reported ever using hypothermia in resuscitated, unconscious cardiac arrest survivors was 95 out of $202(47.0 \%, 95 \%$ CI $40.8 \%-53.2 \%$ ) (Table 2). Forty-five of 247 respondents did not answer this question. The ED was the most common site where induced hypothermia was initiated (64.9\%), followed by the intensive care unit (ICU) (33.9\%). Cardiac arrest dysrhythmias for which induced hypothermia would "usually" be initiated included ventricular fibrillation $(56.0 \%)$ and ventricular tachycardia $(52.3 \%)$. Ice packs and cooling blankets were the predominant method of cooling in the ED.

Sedation with midazolam or propofol and paralysis were commonly cited adjuncts to cooling. Only a few respondents indicated that sedation or paralytics would not be used (Table 2).

Policies and protocols were present in 66 out of 112 $(58.9 \%, 95 \%$ CI $48.9 \%-68.0 \%)$ of respondents from academic centres, compared with 20 out of $71(28.2 \%, 95 \%$ CI $17.7 \%-38.6 \%$ ) of respondents from nonacademic centres. Overall, respondents who worked in centres with a policy or protocol were more likely to have cooled patients (66 out of $86,76.7 \%$; $95 \%$ CI $66 \%-87.4 \%$ ) than those who worked in other centres (23 out of 96, 23.9\%; $95 \%$ CI $15.5-32.4 \%)$.

Respondents indicated that the most common barriers to cooling were a lack of policies and protocols (38.9\%) and of resources (29.4\%). Other "most common" barriers cited included disagreement between specialties (8.7\%), lack of evidence $(7.9 \%)$, difficult to initiate $(5.6 \%)$, administrative hurdles (3.2\%) and nursing issues (1.6\%). The association between each preselected predictor variable and having cooled a patient is shown in Table 3 . The only statistically significant predictor retained in the stepwise selection process was the presence of a protocol or policy for cooling (unadjusted odds ratio [OR] 10.5, 95\% CI 5.3-20.8; $p<0.001$ ). The fit of this model was adequate (HosmerLemeshow $\chi^{2}=2.1 ; p=0.38$ ).

\section{Discussion}

We found that only one-half of Canadian emergency physicians reported ever having induced hypothermia for cardiac arrest victims. When used, hypothermia was initiated in the ED approximately two-thirds of the time and almost always included sedation, paralysis and ice packs. Hospital policies and protocols for induced hypothermia were more commonly present in academic centres.

\begin{tabular}{|c|c|}
\hline Characteristic & No. (and \%) of responses \\
\hline \multicolumn{2}{|l|}{ Sex; $n=246 *$} \\
\hline Male & $181(73.6)$ \\
\hline Female & $65(26.4)$ \\
\hline \multicolumn{2}{|l|}{ Age, yr; $n=246^{*}$} \\
\hline$<36$ & $69(28.0)$ \\
\hline $36-45$ & $112(45.5)$ \\
\hline$>45$ & $65(26.4)$ \\
\hline \multicolumn{2}{|c|}{ Certification; $n=240 *$} \\
\hline CCFP & $30(12.5)$ \\
\hline CCFP(EM) & $115(47.9)$ \\
\hline FRCP & $62(25.8)$ \\
\hline Othert & $33(13.8)$ \\
\hline \multicolumn{2}{|c|}{ Hospital type; $n=247^{*}$} \\
\hline Academic & $149(60.3)$ \\
\hline Nonacademic & $98(39.7)$ \\
\hline \multicolumn{2}{|c|}{$\begin{array}{l}\text { Estimated annual ED visits; } \\
n=244^{*}\end{array}$} \\
\hline$<10000$ & $2(0.8)$ \\
\hline $10000-30000$ & $45(18.4)$ \\
\hline $30000-50000$ & $86(35.2)$ \\
\hline$>50000$ & $111(45.5)$ \\
\hline \multicolumn{2}{|c|}{$\begin{array}{l}\text { Cardiac arrest victims/yr; } \\
n=205^{*}\end{array}$} \\
\hline$<25$ & $39(19.0)$ \\
\hline $25-75$ & $67(32.7)$ \\
\hline $75-150$ & $65(31.7)$ \\
\hline$>150$ & $34(16.6)$ \\
\hline
\end{tabular}

$E D=$ emergency department

*No. of respondents who answered question.

†16/33 of "other" were resident physicians. 
Frequently cited barriers were the lack of policy or protocol or resources available. On multivariate analysis, the presence of a policy or protocol was strongly associated

\section{Table 2. Survey responses by Canadian emergency} physicians regarding induced hypothermia

Survey question No. (and \%) of responses*

\begin{tabular}{|c|c|}
\hline \multicolumn{2}{|c|}{$\begin{array}{l}\text { "Have you cooled patients after } \\
\text { cardiac arrest?"; } n=202 \dagger\end{array}$} \\
\hline Yes & $95(47.0)$ \\
\hline No & $107(53.0)$ \\
\hline \multicolumn{2}{|c|}{$\begin{array}{l}\text { "Where is induced hypothermia } \\
\text { initiated?"; } n=171 \dagger\end{array}$} \\
\hline Prehospital & $2(1.2)$ \\
\hline ED & $111(64.9)$ \\
\hline Ward & $0(0)$ \\
\hline ICU & $58(33.9)$ \\
\hline \multicolumn{2}{|l|}{$\begin{array}{l}\text { "Which patients are treated } \\
\text { with induced hypothermia?" } \\
\text { (always or usually)* }\end{array}$} \\
\hline $\mathrm{VF} ; n=184$ & $103(56.0)$ \\
\hline $\mathrm{VT} ; n=174$ & $91(52.3)$ \\
\hline Asystole; $n=169$ & $41(24.3)$ \\
\hline $\mathrm{PEA} ; n=172$ & $40(23.3)$ \\
\hline \multicolumn{2}{|l|}{$\begin{array}{l}\text { Agents most commonly used in } \\
\text { sedating patients } \ddagger \text {; }=83 \dagger\end{array}$} \\
\hline Midazolam & $37(44.6)$ \\
\hline Propofol & $31(37.3)$ \\
\hline None & $4(4.8)$ \\
\hline Fentanyl & $3(3.6)$ \\
\hline Morphine & $3(3.6)$ \\
\hline Etomidate & $3(3.6)$ \\
\hline Diazepam & $2(2.4)$ \\
\hline \multicolumn{2}{|c|}{$\begin{array}{l}\text { Agents most commonly used for } \\
\text { paralysis in patients being } \\
\text { treated with } \mathrm{IH} \neq ; n=79 \dagger\end{array}$} \\
\hline Rocuronium & $41(51.9)$ \\
\hline Pancuronium & $12(15.2)$ \\
\hline None & $11(13.9)$ \\
\hline Succinylcholine & $10(12.7)$ \\
\hline Atracurium & $3(3.8)$ \\
\hline Vecuronium & $2(2.5)$ \\
\hline \multicolumn{2}{|l|}{$\begin{array}{l}\text { "How do you cool your } \\
\text { patients?" (always or usually)* }\end{array}$} \\
\hline Ice packs; $n=86$ & $81(94.2)$ \\
\hline Cooling blanket; $n=70$ & $57(81.4)$ \\
\hline Cold saline; $n=65$ & $35(53.8)$ \\
\hline Mists and fans; $n=60$ & $32(53.3)$ \\
\hline Cooled mattresses; $n=55$ & $16(29.1)$ \\
\hline Other (lavage, heat & $2.2(4.4)$ \\
\hline
\end{tabular}

with a self-report of having induced hypothermia.

Victims of sudden cardiac arrest can survive neurologically intact, but this outcome is uncommon., ${ }^{3,17,18}$ The ED management of these patients is evolving beyond primarily rhythm-based therapies to focus on neurological resuscitation. ${ }^{10}$ Inducing mild hypothermia (core temperature $32^{\circ} \mathrm{C}-34^{\circ} \mathrm{C}$ ) has been demonstrated to improve both neurological outcomes and mortality. ${ }^{8,9}$ Systematic reviews have estimated numbers needed to treat of 6 for each excellent neurologic outcome and 7 for each survivor. The AHA and ILCOR recommend mild hypothermia for ventricular fibrillation (grade IIa) and for nonventricular fibrillating rhythms (grade IIb). ${ }^{10,11,19}$

Despite this evidence and these recommendations, physicians have been slow to incorporate this procedure into their practice. ${ }^{15,16}$ In 2003, Abella and colleagues ${ }^{16}$ undertook an internet-based survey of randomly selected US physicians from the Society for Academic Emergency Medicine, the American Thoracic Society and the American Heart Association. In total, 265/1400 (19\%) surveys were completed and included physicians practising emergency medicine $(41 \%)$, critical care $(13 \%)$, cardiology (24\%) and other disciplines (22\%). Of respondents, $78 \%$ practised in tertiary care or academic medical centres. Only $13 \%$ of respondents overall and $4.6 \%$ of the emergency physicians had initiated hypothermia after arrest. Major factors cited for not instituting induced hypothermia included "lack of evidence" (49\%), "lack of incorporation into advanced cardiac life support (ACLS) protocols" (32\%) and "too technically difficult/slow" (28\%). The role of a local protocol was not established, although $8.8 \%$ reported being in the process of developing one.

In the same year, Merchant and colleagues ${ }^{15}$ conducted a web-based survey of physicians from the United States, United Kingdom and Finland. A total of 13272 surveys were distributed and 2248 (17\%) were completed. Physicians practised critical care (35\%), cardiology (20\%), emergency medicine (22\%) and other fields (22\%). In all, 26\% of all US and $36 \%$ of the non-US respondents reported having used hypothermia following cardiac arrest. Only $16 \%$ (95\% CI $12.6 \%-19.4 \%$ ) of the 438 emergency physicians from the United States had used cooling as a treatment. Reasons for lack of use were similar to those reported by Abella and colleagues, ${ }^{16}$ with "not enough data" (49\% US, $41 \%$ non-US), "too technically difficult" (35\% US, 32\% non-US) and "not part of ACLS" (41\% US, 26\% non-US) being the predominant choices. The use of protocols and policies was not reported.

Our study suggests that more emergency physicians in Canada have induced therapeutic hypothermia, compared 
with previous surveys, ${ }^{15,16}$ despite similar response rates and methodology. Three times more Canadian emergency physicians reported having induced hypothermia than the overall rate reported by Merchant and co-authors. ${ }^{15}$ In both surveys, the majority of respondents practised in tertiary or academic centres and managed more than 10 cardiac arrest victims per year.

It seems likely that this increased rate is due to lags in knowledge translation. While the primary evidence base supporting hypothermia following cardiac arrest has remained relatively stable since $2002,{ }^{8,9}$ greater educational opportunities, the publication of the CAEP position statement, ${ }^{14}$ the 2005 ACLS guidelines ${ }^{10}$ and the passage of time appear to have afforded more physicians the opportunity to incorporate hypothermia induction into their practice.

Despite these factors, about one-half of respondents have never cooled patients after cardiac arrest. Beyond patient selection and limited opportunity for use, other factors were also reported. In contrast with the previous studies, our respondents reported that the absence of local protocol, policies and resources were the most common barriers to therapeutic hypothermia. Moreover, the existence of local policies or protocols had the strongest association with the use of hypothermia. The CAEP Critical Care Committee published guidelines for the use of hypothermia after cardiac arrest in 2005 and 2006. ${ }^{12,14}$ We believe these documents may be useful for the local implementation of induced hypothermia in EDs. These guidelines reinforce the recommendations put forth by $\mathrm{ILCOR}^{11}$ and the AHA, ${ }^{10}$ and they provide a foundation for institutions to adopt a policy or protocol for the use of hypothermia in cardiac arrest victims. Notably, a small number of respondents cited limited support from other specialties as an impediment to the use of induced hypothermia. Continued education and collaboration may lead to a more uniform approach for induced hypothermia.

Induced hypothermia appears to be perceived as being labour or resource intensive. Although little specialized equipment is necessary, ${ }^{20}$ scarcity of ED resources was identified as an important deterrent. Future research should quantify the resources needed to initiate induced hypothermia in the ED.

\section{Limitations}

This study is an Internet-based survey and is therefore subject to the associated limitations. Internet-based surveys are dependent on a web-based database, the accuracy of email distribution lists, computer use and skills of respondents. Response rate was low despite multiple sendouts but is consistent with previous studies. While selection bias may have influenced respondents and certain centres may be overrepresented, we are unable to test for this at the level of the respondent and preserve anonymity. We did not compare the demographics of the survey respondents to CAEP membership overall.

\section{Conclusion}

Only about one-half of Canadian emergency physicians report having cooled a cardiac arrest victim. The implementation

\begin{tabular}{|c|c|c|c|}
\hline \multirow[b]{2}{*}{ Independent variable (reference group) } & \multicolumn{2}{|c|}{$\begin{array}{c}\text { No. of } \\
\text { physicians who } \\
\text { have cooled } \\
\text { patients }\end{array}$} & \multirow[b]{2}{*}{ Crude OR $(95 \% \mathrm{Cl})$} \\
\hline & Yes & No & \\
\hline \multicolumn{4}{|l|}{ Policy/protocol (no policy) } \\
\hline Yes & 66 & 20 & $10.5(5.3-20.8)$ \\
\hline No & 23 & 73 & \\
\hline \multicolumn{4}{|c|}{ FRCP/CCFP(EM)/ABEM (not emergency medicine certified) } \\
\hline Yes & 83 & 77 & $4.2(1.8-9.6)$ \\
\hline No & 8 & 31 & \\
\hline \multicolumn{4}{|l|}{ Academic hospital (not academic affiliated) } \\
\hline Yes & 69 & 59 & $2.2(1.2-3.9)$ \\
\hline No & 26 & 48 & \\
\hline \multicolumn{4}{|l|}{ > 50000 ED visits/yr (<50 000 ED visits/yr) } \\
\hline Yes & 55 & 36 & $2.7(1.5-4.8)$ \\
\hline No & 40 & 71 & \\
\hline
\end{tabular}


of a local policy or protocol is strongly associated with the use of induced hypothermia for cardiac arrest victims by Canadian emergency physicians.

Acknowledgements: The authors would like to thank the following members of the CAEP Critical Care Committee for their contributions to the development of this study: Dr. D. Howes, Dr. S. Gray, Dr. D. Easton.

Competing interests: None declared.

\section{References}

1. Becker LB, Smith DW, Rhodes KV. Incidence of cardiac arrest: a neglected factor in evaluating survival rates. Ann Emerg Med 1993;22:86-91.

2. Vreede-Swagemakers JJ, Gorgels AP, Dubois-Arbouw WI, et al. Out-of-hospital cardiac arrest in the 1990's: a population-based study in the maastricht area on incidence, characteristics and survival. J Am Coll Cardiol 1997;30:1500-5.

3. Holzer M, Bernard SA, Hachimi-Idrissi S, et al. Hypothermia for neuroprotection after cardiac arrest: systematic review and individual patient data meta-analysis. Crit Care Med 2005;33:414-8.

4. Stiell IG, Wells GA, DeMaio VJ, et al. Modifiable factors associated with improved cardiac arrest survival in a multicenter basic life support/defibrillation system: OPALS study phase I results. Ontario prehospital advanced life support. Ann Emerg Med 1999;33:44-50.

5. Herlitz J, Ekstrom L, Wennerblom B, et al. Effect of bystander initiated cardiopulmonary resuscitation on ventricular fibrillation and survival after witnessed cardiac arrest outside hospital. Br Heart J 1994;72:408-12.

6. Cummins RO, Ornato JP, Thies WH, et al. Improving survival from sudden cardiac arrest: the "chain of survival" concept. A statement for health professionals from the advanced cardiac life support subcommittee and the emergency cardiac care committee, american heart association. Circulation 1991;83: $1832-47$

7. Larsen MP, Eisenberg MS, Cummins RO, et al. Predicting survival from out-of-hospital cardiac arrest: a graphic model. Ann Emerg Med 1993;22:1652-8.

8. Bernard SA, Gray TW, Buist MD, et al. Treatment of comatose survivors of out-of-hospital cardiac arrest with induced hypothermia. N Engl J Med 2002;346:557-63.
9. HACA. Mild therapeutic hypothermia to improve the neurologic outcome after cardiac arrest. N Engl J Med 2002;346:549-56.

10. American Heart Association. 2005 American Heart Association Guidelines for Cardiopulmonary Resuscitation and Emergency Cardiovascular Care. Part 7.5: postresuscitation support. Circulation 2005;112:IV-84.

11. Nolan JP, Morley PT, Vanden Hoek TL, et al. Therapeutic hypothermia after cardiac arrest: an advisory statement by the advanced life support task force of the international liaison committee on resuscitation. Circulation 2003;108:118-21.

12. Green RS, Howes D. Hypothermic modulation of anoxic brain injury in adult survivors of cardiac arrest: A review of the literature and an algorithm for emergency physicians. CJEM 2005;7:42-7.

13. Howes D, Green RS, Gray S, et al. Evidence for the use of hypothermia after cardiac arrest. CJEM 2006;8:109-15.

14. Canadian Association of Emergency Physicians; CAEP Critical Care Committee. Guidelines for the use of hypothermia after cardiac arrest. CJEM 2006;8:106-8.

15. Merchant RM, Soar J, Skrifvars MB, et al. Therapeutic hypothermia utilization among physicians after resuscitation from cardiac arrest. Crit Care Med 2006;34:1935-40.

16. Abella BS, Rhee JW, Huang KN, et al. Induced hypothermia is underused after resuscitation from cardiac arrest: a current practice survey. Resuscitation 2005;64:181-6.

17. Xiao F. Bench to bedside: brain edema and cerebral resuscitation: the present and future. Acad Emerg Med 2002;9:933-46.

18. Vaagenes P, Ginsberg M, Ebmeyer UM, et al. Cerebral resuscitation from cardiac arrest: pathophysiologic mechanisms. Crit Care Med 1996;24(Suppl):S57-68.

19. Cheung KW, Green RS, Magee KD. Systematic review of randomized controlled trials of therapeutic hypothermia as a neuroprotectant in post cardiac arrest patients. CJEM 2006;8:329-37.

20. Green RS, Howes DW. Stock your emergency department with ice packs: a practical guide to therapeutic hypothermia for survivors of cardiac arrest. CMAJ 2007;176:759-62.

Correspondence to: Dr. Robert S. Green, Associate Professor, Dalhousie University, Department of Medicine, Division of Critical Care Medicine, and the Department of Emergency Medicine, Rm. 377, Bethune Building, 1278 Tower Rd., Halifax NS B3H 2Y9; greenrs@dal.ca 